\title{
Reactive Oxygen Species and Nitric Oxide in Viral Diseases
}

\author{
ERNST PETERHANS \\ Institute of Veterinary Virology, University of Berne, $\mathrm{CH}-3012$ \\ Berne, Switzerland. E-mail: peterhans@ivv.unibe.ch
}

\begin{abstract}
Metabolites derived from superoxide $\left(\mathrm{O}_{2} \bullet^{-}\right)$and nitric oxide (NO•) play an important role in antimicrobial and antitumoral defense, but may also harm the host. Low levels of such metabolites can also facilitate viral replication because of their mitogenic effects on cells. Most viruses grow better in proliferating cells, and indeed, many viruses induce in their host cell changes similar to those seen early after treatment with mitogenic lectins. Influenza and paramyxoviruses activate in phagocytes the generation of superoxide by a mechanism involving the interaction between the viral surface glycoproteins and the phagocyte's plasma membrane. Interestingly, viruses that activate this host defense mechanism are toxic when injected in the bloodstream of animals. Mice infected with influenza virus undergo oxidative stress. In addition, a wide array of cytokines are formed in the lung, contributing to the systemic effects of influenza. Oxidative stress is seen also in chronic viral infections, such as AIDS and viral hepatitis. Oxidant production in viral hepatitis may contribute to the emergence of hepatocellular carcinoma, a tumor seen in patients after years of chronic inflammation of the liver. Antioxidants and agents that downregulate proinflammatory cytokines and lipid mediators may be a useful complement to specific antiviral drugs in the therapy of viral diseases.
\end{abstract}

Index Entries: Virus; influenza; HIV; hepatitis; therapy; cytokines; antioxidants; nitric oxide; physiology; metabolism.

\section{INTRODUCTION}

The term "reactive oxygen species" (ROS) refers to an array of metabolites derived from molecular oxygen $\left(\mathrm{O}_{2}\right)$, superoxide anion radical $\left(\mathrm{O}_{2}{ }^{\bullet-}\right)$ being the primary one-electron reduction product arising from $\mathrm{O}_{2}$. Superoxide may react with nitric oxide (NO•; formally termed "nitrogen 
monoxide"), an easily diffusible gas derived from arginine by enzymatic reaction (1), or nonenzymatically by direct reduction from nitrite (2), to give nitroperoxide $\left(\mathrm{ONOO}^{-}\right)$. Depending on the relative proportions at which $\mathrm{NO} \bullet$ and $\mathrm{O}_{2} \bullet-$ are produced, $\mathrm{NO} \bullet$ can also act as an antioxidantlimiting lipid peroxidation (3). ROS and nitric oxide with its unstable metabolites termed reactive nitrogen intermediates (RNI) are key elements in antimicrobial and antitumoral defense, but contribute also to aging and the pathogenesis of a wide array of infectious and noninfectious diseases (for a review, see 4). Less well known, but no less important are the multiple roles of ROS and RNI in normal physiology. For example, a low level of ROS is required for mitogenic cell transformation (5), and nitric oxide is a second messenger in brain and involved in the regulation of blood pressure (1). The physiological roles of ROS and RNI are particularly important because viruses, as intracellular parasites, depend on the biosynthetic mechanisms of their host cells. The link between the role of ROS and cell activation began to be appreciated only recently (for a review, see 5), much later than the virucidal effects of viruses (6). First indications that cell activation played a role in viral replication began to emerge at about the same early time, however. Thus, viruses were shown to grow better in lymphocytes treated with mitogenic lectins $(7,8)$ and influenza viruses of the $\mathrm{H} 2 \mathrm{~N} 2$ subtype were found to activate lymphocytes mitogenically (9). In a study on the biochemical effects of Semliki Forest virus on chicken embryo cells, we noted that the alterations induced in mitochondria by this Togavirus were similar to those induced by treatment with fetal calf serum, a well-known mitogenic stimulus (10). Looking for evidence of activation in other cell types, we observed that influenza and paramyxoviruses stimulate a respiratory burst in phagocytic cells. Thus, unaware at that time of the metabolic role of ROS in cell activation, we found that these viruses can activate an effector function of host defense. Activation of ROS generation by influenza and paramyxoviruses in the absence of antiviral antibodies $(11,12)$ was of interest with respect to reports dating back to the 1940s, when these viruses had been shown to induce fever and even hemorrhages in internal organs $(13,14)$. The conditions for the induction of ROS in vitro closely resembled those required for induction of toxic effects in vivo, with no requirement for viral replication in either case. In fact, the similarity extends even further because filamentous influenza virus particles, which are more toxic than spherical ones when injected in animals (15), are also more potent inducers of ROS generation in vitro (16). These observations led us to propose that ROS could play a role in the symptoms and pathology of influenza and other viral infections $(17,18)$.

This concept of viral pathogenesis was put to the test using a mouse model of influenza. Animals infected intranasally develop severe systemic symptoms, including a decrease in body temperature and weight and anorexia, and succumb at days five and six postinfection. The infection remains restricted to the airways and lungs and is characterized by 
massive bronchitis and pneumonia leading to decreased $\mathrm{pO}_{2}$ and increased $\mathrm{pCO}_{2}$ in the blood (unpublished observation). Cells lavaged out of the lung are primed for enhanced ROS production, as shown by the increase in $\mathrm{O}_{2}{ }^{\bullet-}$ release in response to the tumor-promoting agent PMA. As an additional factor contributing to enhanced ROS production, the activity of xanthine oxidase, an enzyme generating $\mathrm{O}_{2} \bullet-$, increased in lung homogenates. Analysis of major small molecular antioxidants $(\alpha-$ tocopherol, ascorbate, and glutathione) showed no change in the ratio of reduced to oxidized forms, but the concentrations of antioxidants decreased in the lung during infection, indicating that the antioxidantbuffering capacity diminishes during influenza in mice $(19,20)$. In a more protracted model of influenza, Oda and coworkers showed that intravenously injected pyran copolymer-conjugated superoxide dismutase protects against the lethal effect of influenza (21). Since pyran copolymers are well-known antiviral agents $(22,23)$, this observation is difficult to interpret. Interestingly, as first demonstrated by Bykova and coworkers (24), NO - also seems to play a role in the pathogenesis of influenza, and indeed, it was very recently demonstrated that agents interfering with the formation of $\mathrm{NO} \bullet$ can have a beneficial effect in murine influenza (25).

The role of oxidants in influenza is complicated by several factors, among them the compartmental nature of infection. Even in the airways and lungs, not all regions are affected to the same extent, which poses problems with the conventional biochemical analysis of antioxidants because changes in the microenvironment may not be detected in tissue homogenates. In addition, as mentioned above, although influenza is a local infection of the airways and lung, disease symptoms can be severe both in mice and humans. In humans, influenza is characterized by headache, fever, and myalgia in addition to the respiratory symptoms related to the infection of the respiratory tract (26). Moreover, humans taking certain drugs that are detoxified in the liver may suffer from drug toxicity because of decreased liver function in the course of infection or after vaccination with influenza virus (27). A similar effect was observed also in murine influenza, with a decrease in the demethylation of ${ }^{14} \mathrm{C}$ aminopyrine (unpublished observation). The systemic effects of influenza may be caused by cytokines produced in the lung and released into the bloodstream. In mice infected with influenza virus, we demonstrated in the broncoalveolar lavage fluid a wide array of cytokines and lipid mediators, including tumor necrosis factor (TNF), interleukin-1 (IL-1), interferon- $\gamma$, granulocyte macrophage colony-stimulating factor (GM-CSF), granulocyte colony-stimulating factor (G-CSF), IL-6, and leukotriene B4 (28). It is noteworthy that, in particular, interferons can cause influenzalike symptoms in humans (29).

Although ROS are known to be virucidal $(6,30)$, oxidants could actually increase the titer of infectious influenza virus by a mechanism related to the maturation of the hemagglutinin. This viral surface glyco- 
protein is cleaved intracellularly from a precursor protein, HAo, into its mature form consisting of the disulfide-linked peptides HA1 and HA2. Influenza virus with the immature hemagglutinin HAo may be released from infected cells, but is not infectious. Thus, such virus may bind to a cell, but HAo is unable to mediate the fusion between the viral lipid envelope and the endosomal membrane, leading to the release of the viral core into the cytoplasm. Essential for this fusion is a conformational change in the mature hemagglutinin, which allows the hydrophobic amino-terminal of HA2 to interact with the endosomal membrane. The proportion of infectious to noninfectious virus released from infected cells depends on the amino acid sequence of the hemagglutinin and represents an important feaure of virulence, because it determines the speed of viral propagation in the lung (for a review, see 31). Pulmonary surfactant contains trypsin-like protease(s) capable of cleaving HAo in HA1 and HA2. In healthy uninfected lung, these proteases are neutralized by protease inhibitor (32). In bronchitis and pneumonia, phagocytes increase in numbers in this fluid and produce ROS (33). In a model experiment, we showed that $\mathrm{NaOCl}-$, a highly toxic oxidant produced by phagocytic cells, can oxidize protease inhibitor, thereby indirectly enhancing protease activity. We demonstrated in vitro that the viral titer under such conditions can increase 10,000-fold (20). This experiment may be of relevance to the observation that influenza is more severe in patients suffering from chronic bronchitis (34), a condition known to be associated with enhanced protease activity in the airways. It also illustrates how the virus may use potentially virucidal ROS to its advantage during infection.

Oxidants also influence the pathogenesis of other viral diseases, in particular infection with HIV. Humans infected with HIV are under chronic oxidative stress, as shown by changes in the small molecular antioxidants ascorbic acid, ( $\alpha$-tocopherol, carotenoids, selenium, superoxide dismutase, and in particular, glutathione) (for a review, see 35). Moreover, also pointing to oxidative stress are enhanced plasma levels of hydroperoxides, malondialdehyde, and clastogenic factors $(36,37)$. In vitro, manipulations that result in enhanced oxidative stress enhance the replication of HIV $(38,39)$, possibly via activation of NFKB, a transcription factor that stimulates the replication of HIV and transcription of a number of proinflammatory cytokine genes, among them TNF- $\alpha$ (40). The product of this gene is of particular interest, because its action on cells is linked to the promotion of intracellular oxidative stress, possibly as a result of enhanced ROS production in mitochondria (41) or by lipoxygenase (42). HIV may stimulate ROS production by various mechanisms, including interaction of gp125 with the cell membrane (43) and via Tat, the transactivating protein (44). Furthermore, mycoplasmas, which are known to stimulate HIV replication, may also act by increasing oxidative stress, either by producing $\mathrm{H}_{2} \mathrm{O}_{2}$ (45) or by stimulating the respiratory burst in phagocytic cells in a fashion similar to paramyxoviruses and influenza viruses (46). Finally, coinfection with mycoplas- 
mas and HIV may result in the release of $\mathrm{H}_{2} \mathrm{O}_{2}$ from T-cells (47). The altered redox status seems to contribute to HIV pathogenesis in several ways. As the most dramatic effect, it favors the inexorable and ultimately fatal decrease in the number of CD4 T-cells and many of the immune dysfunctions reported in HIV-infected individuals (for a review, see 35). Much evidence suggests that death of the CD4 T-cells occurs by apoptosis, a process in which oxidants have been shown to play an important role, and that can be prevented or slowed down by antioxidants $(35,48)$.

Several viruses can cause cancer by mechanisms involving oncogenes and tumor suppressor genes (reviewed in 49,50). In addition to these "classical" mechanisms, oxidant stress could also contribute to viral oncogenesis. In particular, several taxonomically diverse viruses cause hepatitis $(51,52)$. Interestingly, only in hepatitis B virus is there convincing evidence for a role of classical mechanisms of viral cancerogenesis (53). Infection with hepatitis viruses may last for years and is accompanied by inflammation, a condition associated with oxidative stress (54). Enhanced levels of ROS and RNI are known to be genotoxic (55). Genotoxic effects may be accentuated by chronic tissue destruction leading to cell proliferation, because the latter results in enhanced fixation of mutations. A similar situation is encountered when potential carcinogens are tested at the maximum tolerated dose (55).

Of particular interest is the formation of $\mathrm{NO} \bullet$ in viral infections of the central nervous system, because NO• formed by inflammatory cells could interfere with the normal role of this gas as a second messenger in neurons (1). Possibly, formation of $\mathrm{NO} \bullet$ could explain some mental alterations seen in many viral infections of the brain. For example, such alterations occur in rabies and in particular in Borna, a viral infection previously known in horses and sheep, and more recently suspected to be a cause of some mental disorders in humans (56). In fact, the severity of neurological signs and degree of inflammatory lesions in the brains of rats with Borna disease were recently shown to correlate with the induction of nitric oxide synthase (57), and the induction of this enzyme was also demonstrated in rabies, allergic encephalomyelitis (58), and lymphocytic choriomeningitis (59). RNI, along with ROS, could also be responsible for neuronal death (60), exemplifying again that these metabolites may have both "metabolic" and toxic effects. Furthermore, in some instances, NO $\bullet$ production may not be induced, but the cells may be primed for enhanced NO synthesis in response to secondary stimuli, as was observed with lymphocytic choriomeningitis (61) and bovine viral diarrhea viruses (62). This effect may be related to the immunosuppression observed during infection in vivo.

Finally, HIV infection (63) and HIV gp120 (64) were shown to enhance the production of NO• in human monocytes and exert neurotoxic effects via $\mathrm{NO} \bullet$ in vitro, respectively. Moreover, NO•-mediated toxicity of HIV and Maedi Visna virus (a lentivirus of sheep) Tat was demonstrated in rats after intracerebral injection $(65,66)$. Although these 
examples would tend to suggest that $\mathrm{NO} \cdot$ may play a negative role in a number of viral infections, NO can also exert antiviral effects $(67,68)$. For example, NO $\bullet$ is thought to mediate antiviral effects of interferon- $\gamma$ against ectromelia, vaccinia, and herpes simplex viruses in mice, as inhibitors of iNOS-abrogated protection (69). Inhibition of viral replication by NO $\bullet$ was also reported for Friend leukemia virus (70) and vesicular stomatitis virus (71).

\section{IS THERE A PLACE FOR ANTIOXIDANTS IN VIRAL DISEASES?}

As discussed above, there is now much evidence that oxidants play a complex role in viral diseases, starting from influences on host cell metabolism and viral replication and extending to desired inactivating effects on viruses and less desired toxic effects on host tissue. Use of antioxidants in the therapy of viral diseases can therefore be expected to act at many different levels. Although for reasons outlined above it has remained difficult to demonstrate changes in the redox status of small molecular antioxidants, recent observations indicate that clear deficits in antioxidants can have quite dramatic effects on the outcome of viral infections. Most remarkable is the observation that mice made deficient in selenium and vitamin E may be killed by Coxsackie virus strains, which are harmless in selenium-sufficient animals. The unexpected observation that a number of animals inoculated with an attenuated strain produced a virulent strain capable of also killing animals sufficient in selenium and vitamin E suggests that the antioxidant status of a host may even influence viral evolution by as yet unknown mechanisms (72-74). Antioxidants, particularly when given in a blend and at proportions present in a balanced diet of fruits and vegetables, are not toxic, and no untoward effects are to be expected from their use as a supportive adjunct to conventional therapy in viral diseases. Whether this is also true for synthetic antioxidants, like BHT, is less clear, as indicated by the observation that this antioxidant prevented the immune response of chickens to Newcastle disease virus. Interestingly, BHT also prevented the lethal effect of this virus in birds (75).

A therapy should also target additional mechanisms that contribute to the symptoms and pathology of viral diseases, such as certain cytokines, NO•, and lipid mediators. Of course, one could argue that this approach fails to interfere directly with the replication of the virus, and would therefore simply extend the old-fashioned "symptomatic" therapy that is based on agents, such as aspirin. This criticism fails to take into account that:

1. In acute viral infections, symptoms lag behind the maximum phase of viral replication; 
2. With rare exceptions, antiviral drugs that match the specificity and, in particular, the low host toxicity of antibiotics used to combat bacteria are still not available; and

3. Such a therapy would have a sound scientific basis, because it rests on understanding of the mechanisms causing disease symptoms and pathology.

Finally, one could also argue that, irrespective how old-fashioned a therapy based on a simple drug such as aspirin may be, it has shown beneficial effects in millions of humans suffering from the common cold. Surely, such an approach would not make unneccessary a further search for better antivirals, particularly with severe infections, such as hepatitis or encephalitis.

\section{ACKNOWLEDGMENTS}

I thank Giuseppe Bertoni and Thomas W. Jungi for critically reading the manuscript. This work was supported by Swiss National Fund grant 31-39733.93.

\section{REFERENCES}

1. D. S. Bredt, and S. H. Snyder, Nitric oxide: a physiologic messenger molecule, Annu. Rev. Biochem. 63, 175-195 (1994).

2. J. L. Zweier, P. Wang, A. Samouilov, and P. Kuppusamy, Enzyme-independent formation of nitric oxide in biological tissues (see comments), Nature Med. 1, 804-809 (1995).

3. V. Darley-Usmar, H. Wiseman, and B. Halliwell, Nitric oxide and oxygen radicals: a question of balance, FEBS Lett. 369, 131-135 (1995).

4. B. Halliwell, J. M. C. Gutteridge, and C. E. Cross, Free radicals, antioxidants, and human disease--where are we now, J. Lab. Clin. Med. 119, 598-620 (1992).

5. R. H. Burdon, Superoxide and hydrogen peroxide in relation to mammalian cell proliferation, Free Radical Biol. Med. 18, 775-794 (1995).

6. M. E. Belding, S. J. Klebanoff, and C. G. Ray, Peroxidase-Mediated virucidal systems, Science 167, 195-196 (1970).

7. E. F. Wheelock, and S. T. Toy, Participation of lymphocytes in viral infections, Adv. Immunol. 16, 123-184 (1973).

8. J. F. Woodruff, and J. J. Woodruff, T lymphocyte interaction with viruses and virusinfected tissues, Prog. Med. Virol. 19, 120-160 (1975).

9. G. M. Butchko, R. B. Armstrong, W. J. Martin, and F. A. Ennis, Influenza A viruses of the H2N2 subtype are lymphocyte mitogens, Nature 271, 65-67 (1978).

10. E. Peterhans, E. Haenggeli, P. Wild, and R. Wyler, Mitochondrial calcium uptake during infection of chicken embryo fibroblasts with Semliki Forest virus, J. Virol. 29, 143-152 (1979).

11. E. Peterhans, Sendai virus stimulates chemiluminescence in mouse spleen cells, Biochem. Biophys. Res. Commun. 91, 383-392 (1979).

12. E. Peterhans, Chemiluminescence: an early event in the interaction of Sendai and influenza viruses with mouse spleen cells. I. The role of the envelope glycoproteins in the stimulation of chemiluminescence, Virology 105, 445-455 (1980).

13. W. Henle, and G. Henle, The toxicity of influenza virus, Science 102, 398-400 (1945). 
14. I. L. Bennet, R. R. Wagner, and V. S. Lequire, Pyrogenicity of influenza virus in rabbits, Proc. Soc. Exp. Biol. Med. 71, 132-133 (1949).

15. J. M. Edney, Studies on the toxicity of influenza viruses, $\mathrm{PhD}$ thesis, University of London (1955).

16. E. Peterhans, F. Mettler, and E. Manser, The effect of virus particle size on chemiluminescence induction by influenza and Sendai-viruses in mouse spleen cells, Free Radical Res. Commun. 11, 11-22 (1990).

17. E. Peterhans, M. Grob, T. Bürge, and R. Zanoni, Virus-induced formation of reactive oxygen intermediates in phagocytic cells, Free Radical Res. Commun. 3, 39-46 (1987).

18. E. Peterhans, T. W. Jungi, and R. Stocker, Autotoxicity and reactive oxygen in viral disease, in Oxy-Radicals in Molecular Biology and Pathology, UCLA Symposia on Molecular and Cellular Biology, New Series, vol. 82, P. A. Cerutti, I. Fridovich, and J. M. McCord, eds., pp. 543-562 (1988).

19. G. D. Buffinton, S. Christen, E. Peterhans, and R. Stocker, Oxidative stress in lungs of mice infected with influenza A virus, Free Radical Res. Commun. 16, 99-110 (1992).

20. T. Hennet, E. Peterhans, and R. Stocker, Alterations in antioxidant defences in lung and liver of mice infected with influenza A virus, J. Gen. Virol. 73, 39-46 (1992).

21. T. Oda, T. Akaike, T. Hamamoto, F. Suzuki, T. Hirano, and H. Maeda, Oxygen radicals in influenza-induced pathogenesis and treatment with pyran polymerconjugated SOD, Science 244, 974-976 (1989).

22. P. S. Morahan, A. Pinto, D. Stewart, D. M. Murasko, and M. A. Brinton, Varying role of alpha/beta interferon in the antiviral efficacy of synthetic immunomodulators against Semliki Forest virus infection, Antiviral Res. 15, 241-254 (1991).

23. S. C. Kunder, L. Wu, and P. S. Morahan, Protection against murine cytomegalovirus infection in aged mice and mice with severe combined immunodeficiency disease with the biological response modifiers polyribosinic-polycytidylic acid stabilized with L-lysine and carboxymethylcellulose, maleic anhydride divinyl ether and colony stimulating factor 1, Antiviral Res. 21, 233-245 (1993).

24. N. O. Bykova, N. V. Gorbunov, A. A. Bolgarev, M. V. Savina, T. I. Ivanova, M. A. Egoiants, V. F. Vanin, and M. P. Prozorovskaia, Oxidative phosphorylation in liver mitochondria in toxic form of experimental form of influenza, Biull. Eksp. Biol. Med. 112, 617-619 (1991).

25. T. Akaike, Y. Noguchi, S. Ijiri, K. Setoguchi, M. Suga, Y. M. Zheng, B. Dietzschold, and $\mathrm{H}$. Maeda, Pathogenesis of influenza virus-induced pneumonia: involvement of both nitric oxide and oxygen radicals, Proc. Natl. Acad. Sci. USA 93, 2448-2453 (1996).

26. K. G. Nicholson, Clinical features of Influenza, Semin. Respir. Infect. 7, 26-37 (1992).

27. S. Ansher, W. Thompson, and W. Habig, Vaccine-induced alterations in hepatic drug metabolism, Vaccine 9, 277-283 (1991).

28. T. Hennet, H. J. Ziltener, K. Frei, and E. Peterhans, A kinetic study of immune mediators in the lungs of mice infected with iinfluenza-A virus, J. Immunol. 149, 932-939 (1992).

29. I. Dvoretzky, Flulike symptoms with interferon, J. Am. Acad. Dermatol. 22, 321-322 (1990).

30. S. J. Klebanoff, and R. W. Coombs, Viricidal effect of polymorphonuclear leukocytes on human immunodeficiency virus-1-role of the myeloperoxidase system, J. Clin. Invest. 89, 2014-2017 (1992).

31. R. Rott, H. D. Klenk, Y. Nagai, and M. Tashiro, Influenza viruses, cell enzymes, and pathogenicity, Am. J. Respir. Crit. Care Med. 152, 4 Suppl., S16-S19 (1995).

32. H. Kido, K. Sakai, Y. Kishino, and M. Tashiro, Pulmonary surfactant is a potential endogenous infibitor of proteolytic activation of Sendai and influenza a virus, FEBS Lett. 322, 115-119 (1993).

33. K. McCusker, Mechanisms of respiratory tissue injury from cigarette smoking, Am.J. Med. 93 (1A), 18S-21S (1992).

34. F. L. Ruben, and T. R. Cate, Influenza pneumonia, Semin. Respir. Infect. 2, 122-129 (1987).

35. W. Dröge, H. P. Eck, and S. Mihm, Oxidant-antioxidant status in human immunodeficiency virus infection, Oxygen radicals in biological systems, Methods Enzymol. 233, 594-601 (1994). 
36. D. J. Malvy, M. J. Richard, J. Arnaud, A. Favier, and O. Amedee Manesme, relationship of plasma malondialdehyde, vitamin $\mathrm{E}$ and antioxidant micronutrients to human immunodeficiency virus-1 seropositivity, Clin. Chim. Acta 224, 89-94 (1994).

37. J. Fuchs, I. Emerit, A. Levy, L. Cernajvski, H. Schofer, and R. Milbradt, Clastogenic factors in plasma of HIV-1 infected patients, Free Radical Biol. Med. 19, 843-848 (1995).

38. J. Piette, and S. Legrand Poels, HIV-1 reactivation after an oxidative stress mediated by different reactive oxygen species, Chem. Biol. Interact. 91, 79-89 (1994).

39. B. Piret, S. Legrand Poels, C. Sappey, and J. Piette, NF-Kappa B transcription factor and human immunodeficiency virus type 1 (HIV-1) activation by methylene blue photosensitization, Eur. J. Biochem. 228, 447-455 (1995).

40. R. Schreck, P. Rieber, and P. A. Baeuerle, Reactive oxygen intermediates as apparently widely used messengers in the activation of the NF-Kappa-B transcription factor and HIV-1, EMBO J. 10, 2247-2258 (1991).

41. T. Hennet, C. Richter, and E. Peterhans, Tumour necrosis factor-alpha induces superoxide anion generation in mitochondria of L929 cells, Biochem. J. 289, 587-592 (1993).

42. V. B. O'Donnell, S. Spycher, and A. Azzi, Involvement of oxidants and oxidantgenerating enzyme(s) in tumour-necrosis-factor-alpha-mediated apoptosis: role for lipoxygenase pathway but not mitochondrial respiratory chain, Biochem. J. 310, 133-141 (1995).

43. D. Pietraforte, E. Tritarelli, U. Testa, and M. Minetti, Gp120 HIV envelope glycoprotein increases the production of nitric oxide in human monocyte-derived macrophages, J. Leukocyte Biol. 55, 175-182 (1994).

44. M. O. Westendorp, V. A. Shatrov, K. Schulze Osthoff, R. Frank, M. Kraft, M. Los, P. H. Krammer, W. Droge, and V. Lehmann, HIV-1 Tat potentiates TNF-induced NFkappa B activation and cytotoxicity by altering the cellular redox state, Embo J. 14, 546-554 (1995).

45. S. Arai, T. Munakata, and K. Kuwano, Mycoplasma interaction with lymphocytes and phagocytes: role of hydrogen peroxide released from M. pneumoniae, Yale J. Biol. Med. 56, 631-638 (1983).

46. P. Köppel, E. Peterhans, G. Bertoni, R. Keist, P. Groscurth, R. Wyler, and R. Keller, Induction of chemiluminescence during interaction of tumoricidal effector cell populations and tumor cells is dependent on the presence of mycoplasma, J. Immunol. 132, 2021-2029 (1984).

47. J. Chochola, A. D. Strosberg, and M. Stanislawski, Release of hydrogen peroxide from human T cell lines and normal lymphocytes co-infected with HIV-1 and mycoplasma, Free Radical Res. 23, 197-212 (1995).

48. G. W. Pace, and C. D. Leaf, The role of oxidative stress in HIV disease, Free Radical Biol. Med. 19, 523-528 (1995).

49. M. L. Linial, and M. Emerman, RNA tumor virus update, Cancer Cells-A Monthly Rev. 3, 351-354 (1991).

50. K. H. Vousden, and P. J. Farrell, Viruses and human Cancer, Br. Med. Bull. 50, 560-581 (1994).

51. Anonymus. The A to F of viral hepatitis, Lancet 336, 1158-1160 (1990).

52. A. J. Zuckerman, The new GB hepatitis viruses, Lancet 345, 1453-1454 (1995).

53. D. R. Milich, J. Jones, J. Hughes, and T. Maruyama, Hepatitis B virus infection, the immune response and hepatocellular carcinoma, Ciba Found. Symp. 187, 113-129 (1994).

54. H. Ohshima, and $\mathrm{H}$. Bartsch, Chronic infections and inflammatory processes as cancer risk factors: possible role of nitric oxide in carcinogenesis, Mutat. Res. 305, 253-264 (1994).

55. B. N. Ames, L. S. Gold, and W. C. Willett, The causes and prevention of cancer, Proc. Natl. Acad. Sci. USA 92, 5258-5265 (1995).

56. R. Rott, S. Herzog, B. Fleischer, A. Winokur, J. Amsterdam, W. Dyson, and H. Koprowski, Detection of serum antibodies to Borna disease virus in patients with psychiatric disorders, Science 228, 755-756 (1985).

57. M. Z. Yong, M. K. H. Schafer, E. Weihe, S. Hai, S. Corisdeo, F. F. Zhen, H. Koprowski, and $\mathrm{B}$. Dietzschold, Severity of neurological signs and degree of inflammatory lesions 
in the brains of rats with Borna disease correlate with the induction of nitric oxide synthase, J. Virol. 67, 5786-5791 (1993).

58. D. C. Hooper, S. T. Ohnishi, R. Kean, Y. Numagami, B. Dietzschold, and H. Koprowski, Local nitric oxide production in viral and autoimmune diseases of the central nervous system, Proc. Natl. Acad. Sci. USA 92, 5312-5316 (1995).

59. I. L. Campbell, A. Samimi, and C. S. Chiang, Expression of the inducible nitric oxide synthase. Correlation with neuropathology and clinical features in mice with lymphocytic choriomeningitis, J. Immunol. 153, 3622-3629 (1994).

60. V. L. Dawson, and T. M. Dawson, Free radicals and neuronal cell death, Cell Death Differ. 3, 71-78 (1996).

61. E. A. Butz, B. S. Hostager, and P. J. Southern, Macrophages in mice acutely infected with lymphocytic choriomeningitis virus are primed for nitric oxide synthesis, Microb. Pathog. 16, 283-295 (1994).

62. H. Adler, B. Frech, P. Meier, T. W. Jungi, and E. Peterhans, Noncytopathic strains of bovine viral diarrhea virus prime bovine bone marrow-derived macrophages for enhanced generation of nitric oxide, Biochem. Biophys. Res. Commun. 202, 1562-1568 (1994).

63. M. I. Bukrinsky, H. S. Nottet, H. Schmidtmayerova, L. Dubrovsky, C. R. Flanagan, M. E. Mullins, S. A. Lipton, and H. E. Gendelman, Regulation of nitric oxide synthase activity in human immunodeficiency virus Type 1 (HIV-1)-infected monocytes: implications for HIV-associated neurological disease, J. Expl. Med. 181, 735-745 (1995).

64. V. L. Dawson, T. M. Dawson, G. R. Uhl, and S. H. Snyder, Human immunodeficiency virus type 1 coat protein neurotoxicity mediated by nitric oxide in primary cortical cultures, Proc. Natl. Acad. Sci. USA 90, 3256-3259 (1993).

65. M. G. Hayman, Arbuthnott, G. Harkiss, H. Brace, P. Filippi, V. Philippon, D. Thomson, R. Vigne, and A. Wright, Neurotoxicity of peptide analogues of the transactivating protein Tat from Maedi-Visna virus and human immunodeficiency virus, Neuroscience 53, 1-6 (1993).

66. V. Philippon, C. Vellutini, D. Gambarelli, G. Harkiss, G. Arbuthnott, D. Metzger, R. Roubin, and P. Filippi, The basic domain of the Lentiviral Tat protein is responsible for damages in mouse brain: involvement of cytokines, Virology 205, 519-529 (1994).

67. K. D. Croen, Evidence for antiviral effect of nitric oxide, inhibition of herpes simplex virus type 1 replication, J. Clin. Invest. 91, 2446-2452 (1993).

68. J. B. Mannick, The antiviral role of nitric oxide, Res. Immunol. 146, 693-697 (1995).

69. G. Karupiah, Q. W. Xie, R. M. L. Buller, C. Nathan, C. Duarte, and J. D. Macmicking, inhibition of viral replication by interferon-gamma induced nitric oxide synthase, Science 261, 1445-1448 (1993).

70. K. Akarid, M. Sinet, B. Desforges, and M. A. Gougerot Pocidalo, Inhibitory effect of nitric oxide on the replication of a murine retrovirus in vitro and in vivo, J. Virol. 69, 7001-7005 (1995).

71. Z. B. Bi, and C. S. Reiss, Inhibition of vesicular stomatitis virus infection by nitric oxide, J. Virol. 69, 2208-2213 (1995).

72. M. A. Beck, P. C. Kolbeck, L. H. Rohr, Q. Shi, V. C. Morris, and O. A. Levander, Vitamin E deficiency intensifies the myocardial injury of Coxsackievirus B3 infection of mice, J. Nutr. 124, 345-358 (1994).

73. M. A. Beck, P. C. Kolbeck, L. H. Rohr, Q. Shi, V. C. Morris, and O. A. Levander, Benign Human Enterovirus Becomes Virulent in Selenium-Deficient Mice, J. Med. Virol. 43, 166-170 (1994).

74. M. A. Beck, Q. Shi, V. C. Morris, and O. A. Levander, Rapid genomic evolution of a non-virulent Coxsackievirus B3 in selenium-deficient mice results in selection of identical virulent isolates, Nature Med. 1, 433-436 (1995).

75. M. Brugh, Jr., Butylated hydroxytoluene protects chickens exposed to Newcastle disease virus, Science 197, 1291-1292 (1977). 